\title{
Culture or Context?
}

\section{Comparing Recent Trajectories of Elder Care Development in China and Taiwan}

\author{
Alex Payette \\ University of Toronto, Toronto, Ontario, Cananda \\ Yi-Chun Chien \\ National Chengchi University, Taipei, Taiwan, China
}

\begin{abstract}
Policy legacies are an important factor explaining how, regardless of the nontraditional discourse, previously implemented laws and policies have greatly influenced the state of eldercare arrangements in both China and Taiwan. On the one hand, Taiwan has been shifting eldercare responsibilities from the family to the public through a series of social policy reforms fueled by political demands from the civil society since its democratic transition, whereas the Chinese Party-State enacted a series of filial laws in addition to reform policies, which inflated the demand and supply for familial care while at the same time impacting the development of institutional eldercare. While the issue often framed as the prevalence of filial culture in Chinese societies, this article argues, through a path dependency-based perspective, that legal provisions, policies and the structure of the political competition are largely responsible for shaping current eldercare arrangements on both sides of the strait.
\end{abstract}

\section{Keywords}

Asian values - elder care - policy legacies - path dependency

Why did two "culturally Chinese" societies develop such different care arrangements for the elderly? The provision of elder care, insofar as it currently represents a pressing issue in East Asian societies, has long been tied to cultural 
particularism. This type of explanation-based on the cultural variable-was and remains favoured by proponents of the cultural approach, under the guise of the infamous "Asian values" notion. According to the latter, culture alone should be sufficient to explain not only variations between different societies (e.g., Western and Asian societies), but also commonalities that ought to be found between, in our case, "Asian" societies. To this effect, we would expect China and Taiwan to exhibit strong similarities in terms of eldercare arrangements, as both of them are generally categorised as "culturally Chinese societies". However, there seems to be considerable differences between these two, distinctions which we argue can mainly be explained through the lens of recent policy legacies. ${ }^{1}$ Unlike the proponents of the cultural variable, we posit that recent policy legacies-more specifically legal provisions, policies, and the structure of political competition - are largely responsible for shaping current eldercare arrangements on both sides of the strait.

On the one hand, during the early 1980s, the Communist Party-State implemented a variety of "filial" laws and regulations, decentralised social expenditures, and pension provisions, thus creating a self-reinforcing informal care structure instead of developing institutional care. To a certain extent, the early reform-oriented agenda led to policies favouring familial care instead of traditional filial culture, explaining in part the current care crisis. On the other hand, Taiwan's democratic transition in the late 1980 os and the welfare reforms in the 199os had significantly shifted the development of elder care provision away from traditional care arrangements. Since the 20oos, Taiwan has introduced and continues to extend the tax-based and public administered long-term care system to address the problem of its ageing population. The deepening of these social policies within the political system allowed the Taiwanese government to remove and socialise the burden of elder care away from the family to the public, that is, shifting elder care responsibilities from the traditional familial care model to a more socialised one.

As such, our general inquiry focuses on the influence of political and institutional trajectories in similar areas on eldercare provision. Therefore, our article sets out to bring a more theoretical contribution to welfare-state regime literatures in East-Asia by refocusing the argument on recent policy legacies and their effects and consequences.

It is important to note that we are not discarding or even discrediting the role of culture in the construction, and transformations of care arrangements,

1 A similar point was made by Yang (2017) regarding the similar cultural foundations of China and Taiwan, yet their discrepancies in terms of general welfare production. 
nor its influence on welfare provision, or on the structure of certain welfare regimes. For example, a fair amount of research can be found on the topic of cultural influence on local care economies (Bode, 2007; Oorschot et al., 2008). These sets of literature, dating from the early to mid-20oo, were in fact framed as a response to the "omission" of the cultural variable in social science analysis of care (Bode, 2007).

Here, "care" is defined as a range of activities and services that are required to maintain the well-being of the care recipients. As such, care goes beyond the simple healthcare definition (Tremblay and Pernigotti, 2014); it encompasses physical, material, and psychological care provision. In this regard, "care arrangements" are the sum of the modalities under which care is provided (e.g., who provides what kind of care, under what circumstances is care being provided, etc.). In addition, care is often expressed by the "work of care," which in its broadest definition encompasses all the gestures/activities (paid or unpaid) that translate to support provided by one person (or group) in order to help or support someone else livelihood. That said, grasping "care" remains difficult as it is - to loosely quote Professor Ito Peng during the Care and Carework in an Uncaring World meeting (October 2018) - all around us and is sometimes invisible. That said, it is important to note that we mainly focus on eldercare, as an analysis on childcare is beyond the scope of this article would requires another extensive research on the development of the childcare policies that have taken different trajectories in both cases. ${ }^{2}$

To support the aforementioned position, the article proceeds as follows: It first goes back to the "Asian values" literature, underlining its origin, its recent reappraisal, content and how it influences issues such as welfare and care provision in Chinese societies; then it contrasts recent institutional legacies in both China and Taiwan, in order to assess the importance of policies on their current care predicament; then it opens a discussion on the result of this comparison. The objective is to demonstrate the importance of policy legacies on both family and institutional care, while at the same time setting aside the cultural variable and its conceptual subsidiaries.

2 As one might expect, the notion of care, as defined here, does not fully translate into Chinese, in addition to draw upon drastically different lexical fields in both China and Taiwan. That said, what is implied by our definition might be found in the less formal notion of "care"zhaogu 照顾—which implies various forms of material and non-material care. Lastly, it is worth noting that both sides of the straight use very different words to refer to both institutional (medical or not) and informal or even familial care making it difficult to render it in the present article. 
The recent return of the "Asian values" debate, under the guise of the meritocracy versus democracy debate (Bell, 2016; Bell and Li, 2013), has come a long way since the 199os. First advocated by Mahathir Mohamad and Lee Kuan Yew, ${ }^{3}$ the notion of Asian values was set up as a cultural counterargument against Western universalism, but also created a cultural narrative justifying the existence of either "harder" democracies or of "softer" authoritarian regimes in subparts of Asia.

The notion of Asian values usually encompasses elements like the preference for social harmony, hierarchy, loyalty, and, more importantly, collectivism (De Bary, 1998). To a certain extent, Asian values refers to an ensemble of elements loosely based on some form of "Confucianism". More politicised versions of this notion were used by other regimes to fend off the third wave of democratisation back in the early 199 os and to circumvent the human rights discussion. Towards the end of the 199os, the "Asian values" variable was mainly used to explain the "Asian miracle" (also known as the economic growth under the developmental state).

Articles and research on these topics (e.g., human rights, democratisation, etc.) was more than abundant on both sides of the fence (e.g., Bauer and Bell, 1999; Barr, 2002; etc.). At the same time, Asian values became an interesting variable to assess in the welfare state/social policy literature (Goodman et al., 2006; Walker and Wong, 2005; Tang, 200o), in order to bring the Asian experience into perspective of the "Three Worlds" conceptual framework. In the early 2010s, Asian values regained academic interest, and new literature emerged once again (Kim, 2010; Sen, 2014; Welzel, 2011). Since then, Asian values have been used as an explanatory variable on various topics ranging from LGBT rights (Lee, 2016), to mental health and immigration.

Despite having been strongly criticised as cultural overshooting and even sometimes empirically disproven (Kim, 2010; Welzel, 2011), the notion of Asian values remains important in a variety of literature, such as democratisation, and probably the most important at the moment, the topic of welfare regimes and social policy (Abrahmason, 2016; Sung and Pascall, 2014; Lee and Chan, 2010). Although such literature has existed before (Walker and Wong, 2005), it was more trying to define-in accordance with the Three Worlds indicators"Asian welfare regimes" or even possibly "Confucian welfare." ${ }^{4}$ However, these

3 Respectively the Prime Minister of Malaysia from 1981 to 2003 , re-elected in 2018 and the Prime Minister of Singapore from 1959 to 1990.

4 Although taking its origins in the early 199os, the terms "Confucian welfare" or even "Confu- 
focused on the general state of welfare provision in East-Asia, with sometimes less emphasis on its specific components, such as eldercare arrangements.

When discussing the latter, cultural elements become more apparent, especially when the notion of elder care is defined. ${ }^{5}$ For example, plenty of research focus on the Confucian foundations of elder care in China and its influence on contemporary elder care arrangements (Nie, 2015; Fan 2010; Lee, 2015). Similarly, Leung (2014) points out that Confucian values are still very influential in framing care as familial responsibilities Chinese societies, including Taiwan. In this regard, culture-Confucian culture-seems to remain as one of the most important determinants for elder care in Chinese societies even if past legislation might account for the current state of affairs in both China and Taiwan.

As such, social policy and more sociology based literatures (focusing on welfare provision, and care provision) kept using some form of cultural based argument, sometimes pointing to a "Confucian" undertone, in order to explain general care provision, elder care, and even sometimes long-term and end-oflife care arrangements in several east Asian countries. Consequently, this leaves out the more policy-based approaches, which oftentimes use path dependency or process tracing to explain certain institutional arrangements.

\section{3}

\section{Research Design and Argument}

As previously mentioned, we argue that policies and legislation make a stronger case than culture in explaining the trajectory and the degree to which institutional care is developed and made available even under different regime types. That said, regime type does influence how the political struggle is structured, how policies are made, and how they are implemented (Sciubba and Chen, 2017). For example, when a social crisis erupts as a result of past policies' unintended consequences, authoritarian states are faced with a regime crisis, while democracies are faced with a crisis of government. Therefore, policy implementation is not "easier," nor "less risky" under the party-state system, in contrast to democratic Taiwan.

Therefore, this article takes on a path dependency-based approach in order to support our overall demonstration. The central point of this theory is that "choices made when an institution is being formed, or when a policy is being initiated, will have a continuing and largely determining influence ... far into

cian welfare state" owe much to the works of Lin Ka (1999), which became one of the core tenets that illustrates how culture influences welfare trajectories.

5 The comparative study of Yeh, Yi and Tsao (2013) perfectly exemplify this trend. 
the future" (Peters 1999:63). Once an institution or policy is in place, political actors start to adapt to the new rules of the game by making extensive commitments, based on the idea that these rules will continue. High set-up costs associated with the institutions or policies discourage actors from seeking alternatives (e.g., familial care). This framework, we contend, is crucial to understanding the development of elder care arrangements in China and Taiwan. That said, in both cases, policy trajectories seem to account for their current situation, rather than, as others would put it, their shared cultural background.

\section{The Unintended Legacy of the Reforms in the People's Republic}

The general provision of public goods-without diving into public welfare or charity institutions, such as healthcare, as well as the general pension and other types of services (associated to some sort of welfare mix) — was, in both urban and rural areas, set up after 1949 and centred around communes and working units (danwei). The development of the welfare infrastructure emerged side by side with the commune system in rural areas and with more industrial working units in urban areas. Despite major differences in terms of service scope and provision between urban and rural areas, social welfare was provided by the central government and by provinces (ruling over cities, villages, townships, etc.) in a cradle-to-the-grave system for the Chinese workers. In its early days, from 1949 to maybe 1958, the "iron rice bowl" system, which insured employment and benefits to all (even to non-working parties), depicted this state of universal public welfare, ${ }^{6}$ that will come to be dismantled over time, starting with the Great Leap Forward (GLF).

This systematisation of work opportunities and compensation under the state-owned structure was later disrupted during the Great Leap Forward (1958-1962) and again during the Cultural Revolution (1966-1976), to then be progressively curtailed at the beginning of the market-oriented reforms in the early 1980 s. From this moment onwards most of the welfare was being provided by select state-owned enterprises (SOE $)^{7}$ and town-village enterprises (TVE), while other communes were being de-collectivised, slowly privatised, and left

6 Considering that China is more of a de facto federal state than a unitary one (Zheng, 2007), services tended to greatly vary across provinces.

7 Contrary to the more general provisions set out back in 1986 (implementation of pooling for retirement fees) in State-Owned enterprises, (Ma, 1992), the 1991, 1993 and 1997 legislation expended responsibility to the State, the employer and the employees. 
under the Ministry of Civil Affairs or under the newly-reformed Social Insurance System (shehui baoxian zhidu).

From the 199os onwards the People's Republic, on the path to export-oriented industrialisation (EOI), focused on a progressive "social dumping" (e.g., slowly reducing benefits, pensions, and coverage in order to remain competitive, etc.) (Alber and Standing 2000), which culminated before China's entry in the World Trade Organization in 2001. Although some would argue that social security has rapidly increased and improved since then (Wang and Shan, 2015), much of the schemes remain tied to SOE or other small and medium enterprises. Most employers will offer the "five insurances, one fund" (wuxian yijin) — which includes pension, ${ }^{8}$ medical, unemployment, work injury, maternity insurance, and housing funds - which is structured as a co-jointed payment structure by both the worker and the employer. That said, provision differs from province to province and seldom cover long-term care and end-of-life care, and more often than not, offers little protection for rural dwellers. In fact, most provisions only reference "urban workers" (chengzhen). Despite being composed of the character "zhen", which means "villages" or "townships", in this expression it refers to mainly non-agricultural areas, to more commercial intensive locations. It is also worth noting that rural dwellers are 14 times less likely to receive some form of pension than their urban counterparts (Wu and Guo, 2014).

Overall, welfare provision has seen a drastic shift from a more productivist approach in the late 1980s and 1990 s (focused primarily on education and expanding healthcare/pension coverage in urban areas) to a more protective approach (characterised by more social protection and minimum living standards in both urban and rural areas) (Mok et al., 2017). However, elder care in the People's Republic of China, unlike the issue of pensions, healthcare, education, or other types of social goods, took a different turn back in the 1950s, a path that will focus and emphasise a shared responsibility system (between parents and children).

\subsection{Institutional Constraints and Eldercare}

It took only 18 years (1981-1999) for China to join the ranks of the "ageing population" countries (Ren, 2013). In 2000, the 6o-year-old age group made up more than $10 \%$ of the entire population (Zhang and Yan, 2015). With an annual

8 Under the current provisions, pension is solely divided by 120 or 10 years as the calculations are based on the general life expectancy after retirement (i.e. 60 years old +10 years). That said, it is projected that by 2050, $8 \%$ of China's population will be over 80 (Feng and Gliskaya, 2018). 
growth exceeding $3.2 \%$, it is estimated that the latter will represent, in 2050 , $25 \%$ of the world's ageing population (Liu, 2009). The "over 65-year-old group" made up $7 \%$ of the Chinese population in 2005 and it is estimated that they will reach 300 million in 2026, 400 million in 2037, stabilising around 2051 between 300 and 400 million individuals. However, the current support system is under tremendous stress, relying on unequal coverage in terms of both infrastructure and general financial resources.

In this regard, there are two main support system for the elderly in contemporary China, the formal (e.g., state sponsored, work unit sponsored, welfare programmes, etc.) and the informal system, which means family or extended family-based care. As mentioned before, there exist important disparities in terms of public goods provisions between urban and rural areas as well as pension provision issues ${ }^{9}$ leaving the elderly vulnerable, and forcing families to stay together. That said, academic literature has consistently tied the persistence of familial care with remnants of traditional culture, with the Confucian cultural foundations of China. However, if we take a closer look at policy choices and laws enacted by the party-state, this care structure might have been enforced and maintained by design by the party-state, rather than being the product of a distant, often partially invented, cultural heritage.

Following the communists' victory in 1949, the Party enacted the Marriage Law in 1950, which clearly highlighted familial responsibilities for both parents and children, even before completing nationwide collectivisation (which lightly titled the care responsibilities onto the commune/work unit). It is also interesting to note that the Party enforced this set of rules to free the masses from superstitious beliefs ${ }^{10}$ and filial piety (An, 2009), a symbol of the "Confucian" past. The Party also went to great lengths to "destroy" family culture during the Cultural Revolution.

Interestingly enough, the party-state, in the post-Mao era, was keen to redirect eldercare towards the family at the beginning of the de-collectivisation programme. The household responsibility system, established in the early 1980s, shifted elder care (covered by earlier collectivisation) back onto the family unit, while the progressive privatisation of TVE and SOE in the early 199 os reduced budgetary allocations for local/provincial governments to pro-

9 For example, lots of soE have been having issues in providing pensions for their employees in part due to restructuring during privatization or simple insolvability (Cai, Giles and Meng, 2006).

10 Information provided by an eye witness (mister $\mathrm{Li}$ ) who was at the time 25 years old (b.1925) and who went on to be sent down to do manual labor prior to going back to a manufacture around Weifang. (Shandong, April 2019). 
vide pensions (Zhao et al., 2017). While central government and its local counterparts were retreating from welfare provision, the Party enforced several additional provisions insuring the family's position as the main welfare provider. We list four provisions below:

Article 183 (1979) —amended in 1997 as Article 261: Those who have the obligation but refuse to support those who are aged, young, sick, or do not have the ability to live independently, if the case is serious, are to be sentenced to five years or less in prison or put under criminal detention or surveillance;

Constitutional revision of 1982-Article 49: [...] Parents have the duty to rear and educate their minor children, and children who have come of age have the duty to support and assist their parents [...];

Marriage Law of 1980-Article 15: Parents shall have the duty to bring up and educate their children; children shall have the duty to support and assist their parents;

The 1996 (revised in $2012^{11}$ ) Protection of the Rights and Interests of the Elderly-Chapter 2, Articles 13, 14 and 15.

Article 13: The elderly shall be provided for mainly by their families, and their family members shall respect, care for and look after them.

Article 14: Supporters (i.e. the children) of the elderly shall fulfill the obligations of providing for the elderly economically, taking care of them in daily life and comforting them mentally, and attend to their special needs.

Article 15: [...] For the elderly who cannot take care of themselves, their supporters shall bear the responsibility of taking care of them [...].

As privatisation and new market mechanisms were inserted into the Chinese economy, the party-state took institutional and legal measures to "lock-in" families in their "newly" recovered care providing functions. Furthermore, the pension predicament (e.g., low pensions, high prices of nursing homes, etc.) stimulated the demand for home care, and the state, through legal provisions, insured a large inflated "supply" of it while providing low support for the development of a formal institutional care structure.

11 Original law of 1996, amended in 2009, 2012, 2015 and more recently, in December 2018. 
In turn, this situation directly affected, from the mid-1980s onwards, the overall care structure, which includes child care as well. For example, on average, and this was confirmed during multiple interviews, ${ }^{12}$ most children would be sent to out-of-home care institutions (kindergarten) only when having reached three years of age (Stockman et al., 2016); in the meantime, in a majority of cases, retired grandparents (also in need of care) are expected to provide childcare while parents are working. This interlocking of eldercare with childcare reinforces by design this family-centred care structure.

Even when elder care institutions became more available (around the mid199os), the pension issue came back to the forefront. Best pensioners (e.g., from state working units, institutions or organisations) receive a monthly endowment of 4,000 RMB to 10,000 RMB (in addition to medical insurance, etc.). Approximately 83 million individuals had access to this plan back in 2015. In contrast, the basic average urban pension, as of 2012, reached 1,721 RMB per month (Zhang and Yan, 2015). It is estimated that at current prices, elderly people living under home care spend on average 12,0оо Rмв per year for medical treatments and general living costs. This number rises to an average of 25, O00 RMB per year for individuals living in (the cheapest) nursing homes (Du and Liu, 2014). As was explained during a group interview with the Qingdao Elderly Care Service Association (June 2019), nursing homes or simple retirement homes will set you back at least between 5,000 to 7,000 RM B a month in less urbanised areas, and in the case of a Tier 2 cities, like Qingdao, between 10,000 and 20,000 RM B per month. They all underlined that these prices remained "cheap" compared to Beijing, or Shanghai, thus making institutional care inaccessible for most elderly people.

The new rural pension insurance, implemented in 2008, provides a basic living fund of $55 \mathrm{RMB}$ per month. Yet, individuals who wish to participate must pay a premium. This makes the accessibility of care services even more problematic for an already vulnerable population. In rural areas, elder care services are often provided by local charitable groups with limited resources, thereby rendering long-term eldercare services extremely inconsistent and unstable. As such, price is often an important deterrent explaining the high rate of inhome/family care.

This low supply and low demand for institutional elder care - a constantly changing situation-also impacted the general medical situation of the early 1980 s, as well as the medical education sector. As such, most of the staff had

12 Public interviews with three (female) directors of private kindergarten in Qingdao (Shandong, June 2019). 
never been involved in elder care prior to graduation. According to Yu Lanzhen, ${ }^{13}$ from the early 198 os onwards, the priority was on staffing the "new" post-commune medical sector outside of larger urban centres by providing basic training (offered by Tier 1 or Tier 2 city hospital personnel) to county-level and township-level hospitals. Long-term care or even the more specialised curriculum of elder care was not a priority up until the late 199os. As such, up until recently, most nurses lacked proper knowledge and experience in terms of providing long-term care for the elderly.

\subsection{Unintended Consequences by Design?}

When we account for (1) the effects of de-collectivisation and the introduction of market mechanisms back in the early 1980 os (and their effect on the pension system, as well as their influence on the medical sector); (2) subsequent "filial" legislation and legal provisions enacted by the party-state, without even mentioning the "filial education" campaigns launched by the Party (Cheung and Kwan, 2009), the idea that culture is the main reason being the current Chinese care crisis seems a bit far-fetched.

On the contrary, the early days of the reform era (1978-1993) - de-collectivisation, the "one-child policy" (1979), early "filial" laws, decentralisation (19781993) - have largely created today's care crisis. The decentralisation and the subsequent centralisation of fiscal flows after 1994 further exacerbated the issue of social expenditures by local governments (left with less taxation income and more fiscal responsibilities). In turn, fiscal flow re-centralisation has created a dynamic (between the centre and the provinces) that prevents the construction of a coherent social security system.

By "crossing the river while feeling the stone," the party-state and its reactive approach to development, early on set up policies to limit social expenditures. However, these policies have since created a plethora of unintended consequences leading to the current care predicament. And even though Chinese researchers are aware of this, most of the literature remains centred on traditional culture (filial culture) as being the main issue hindering the development of the elder care sector (Zhang, 2012; Zhu and Chen, 2013). As such, nursing, medical, and even most social sciences academic literature focuses on "changing the culture" in order to implement changes.

13 Yu Lanzhen, former Qingdao University Hospital Nursing Department director, who directs and reviews for many Chinese nursing/medicine journals, admitted that the conservation regarding elder care was circular and tend to focus on cultural issues, government funding and local initiatives. https://baike.baidu.com/item/于兰贞. 
The ongoing changes in the elder care structure (the rise of institutional and private sector actors), and the progressive implementation of new social policies (pension, healthcare, etc.) also came as a response to previous policies that created the care crisis. For example, the "one-child policy" is responsible for the progressive miniaturisation of the family structure-in addition to the rising costs of life and the restrictive public good provision structurewhich, in turn, inflated the dependency ratio on China's productive population. This very precarious situation stimulated the demand for out-of-home care, which is currently being met by a progressively growing supply of such care options.

We can think here of the multiplication of "day activity centres," of community service centres, of gated apartment communities for the elderly, of "resorts" for the elderly in addition to local initiatives set up by local governments and/or by local communities. This new offering of care services is sure to, as the Qingdao Elderly Care Service Association representatives put it, compel the next generation of retirees (born in the mid-195os), who benefited from market reforms, to seek out-of-home care in order to alleviate some of the financial pressures bearing down on their children and enjoy living amongst a community of their peers.

\section{$5 \quad$ Taiwan: Competition over Culture}

Similar to many industrialised countries around the world, Taiwan is facing rapid demographic changes - including greater longevity, declining fertility rates, and an ageing population - that create unprecedented challenges in care provision. Since 1993, the proportion of people over the age of 65 has passed the threshold of $7 \%$, which means that Taiwan has officially entered the stage of an ageing society (according to the wHO definition). In 2018, the proportion of the elderly population stood at $14.6 \%$ and is expected to reach $20 \%$ by 2025 .

The first time that Taiwanese government addressed the issue of eldercare was in the early 1980s. During the wake of the third wave of democratisation, the authoritarian regime in Taiwan faced growing demands from the civil society for political liberalisation. Many opponents of the authoritarian regime started to organise into a strong opposition force (which later became the major opposition party) after several political incidents, such as the 228 Incident and the White Terror. Meanwhile, the ruling conservative party, the Kuomintang (КМ or Chinese Nationalist Party) was experiencing a legitimacy crisis as Taiwan was being de-recognised by the international community: (1) it lost 
its seat in United Nations in 1971, and (2) the United States recognised the People's Republic of China in January 1979.

Due to the increasing political challenges (both internal and external) to its legitimacy, the кмт government responded by introducing the Three Acts on Social Welfare in 1980 (Sciubba and Chen, 2017). At the same time, the км т government tailored these social policies to its main supporters who were mostly school teachers, public servants, and military personnel.

For eldercare, Taiwan implemented the Senior Citizens Welfare Act to provide a legal basis for the regulation of eldercare facilities (mostly non-profit organisations). However, in this act, the Taiwanese government had little intention to intervene extensively in service provision. Given fiscal constraints and limited resources, there was a close collaboration between the central and local governments. The former was responsible for setting regulation and financing, while the latter recruited non-profit organisations and social welfare groups to provide services tailored to local preferences. While scholars frequently emphasise "economic development" and "Confucian Asian cultural values" as constituting the two unique contextual pillars in East Asian welfare states, the Taiwanese authoritarian government chose to utilise social welfare policies when faced with political challenges to its legitimacy.

\subsection{Political Legacies, Democracy and Competing Interests}

Since the late 1980s, Taiwan's democratic transition has fundamentally changed the policy-making process of social welfare policies. With democratisation, both political parties and social actors were invited into the policy-making process (Wong, 2004). The KMT conservative government launched welfare reforms immediately after the democratic transition in order to respond to the electoral demands and also to reduce any lasting association with previous authoritarian governments (Wong, 2004; Peng and Wong, 2010). At the same time, the Democratic Progressive Party (DPP), the main grassroots opposition party since the authoritarian period, emphasised social policy issues not only because of their working-class constituency, but also because of the electorate's changing demographics - for example, the increasing number of working women and young voters who show strong preferences for social policy reforms. In other words, all parties worked to secure votes, and more political actors were influencing the social policy-making process.

Thus, between the 199os to early 20oos, the implementation of a universal healthcare system, public pension schemes, and the overall expansion of social policies all point to Taiwanese government's commitment to creating more extensive social welfare institutions. In other words, despite strong Confucian values that emphasise the role of the family in welfare provision, political 
factors-legitimacy crisis, democratic transition, inter-party competitionshave pushed the Taiwanese government to take on a more active role in designing, regulating, and providing social welfare for its own citizens.

The development of eldercare policies was no exception. To respond to the increasing demand to extend eldercare services, in March 200o, Taiwan's Ministry of the Interior launched the Long-Term Care System Development Pilot Project, aimed at developing a long-term service delivery model in selected cities, such as Chaiyi and Sanying (Chien, 2018). Two months later, in May 200o, the Democratic Progressive Party (DPP) was elected for the first time to take office. However, the unemployment rate suddenly increased, going from $2.99 \%$ in 2000 to $4.57 \%$ in 2001 and then to $5.17 \%$ in 2002 . The public blamed the DPP's inexperience and questioned whether the DPP government could stimulate economic growth. In response, the Council of Economic Planning and Development (CEPD) under the Executive Yuan (cabinet) proposed the Care Service Industry Development Project in 2003 to develop the local care market, while channelling local unemployed workers into the care service sector. The DPP government believed this project could solve the problem of unemployment and, at the same time, respond to concerns about an ageing population (Lin, 2010). Here again, the DPP government chose to expand eldercare policies to respond to the political criticisms and did not stand firm on the idea of familial culture for eldercare.

While the Taiwanese government has been actively shifting eldercare responsibilities from the family to the public, it did not plan to be involved extensively in the provision of eldercare services. Unlike the Nordic welfare states that are actively involved in eldercare provision by providing public institutional and community care services, the Taiwanese government intended to increase eldercare commoditisation and marketisation, and retain its regulatory and monitoring role. The goal of the Care Service Industry Development Project was not to place the government in an active role in care provision, but rather to deregulate the care market (i.e., creating a supply of non-traditional care) and the lowering of the barriers to entry in order to attract local investments and workers to the care industry. Through the deregulation and marketisation of eldercare services, the CEP D hoped to expand the coverage of care recipients without increasing the government's fiscal burden. In theory, market competition would encourage service providers to improve the quality of care services. The CEPD asserted that deregulation would increase market options for families with different care needs; this, in turn, would reduce their reliance on migrant care labour and allow the local workforce to enter the care market (Lin, 2010). 


\subsection{From the Family to the Public}

As discussed earlier, democratisation brought multiple political actors into the decision-making process. In addition to the two major political parties, the non-profit organisations and social welfare groups that had been working with local governments to provide care services started to form political alliances to influence political debates surrounding elder care. As Paul Pierson (2000) argues, policy creates a political network — once a policy is implemented, political actors start to adopt the rules of the game and gradually create a selfreinforcing network via increasing returns. Throughout the years, Taiwanese civil society has cultivated strong political networks to influence government policy on elder care.

When the DDP government pushed for the Care Service Industry Development Project, this marketisation policy proposal faced strong opposition from the civil society organisations. The main challenge of the Care Service Industry Development Project was to modify the Senior Citizens Welfare Act (which was implemented back in 1980 during authoritarian rule), as it only allowed non-profit organisations and small for-profit organisations (with fewer than $5^{\circ}$ patients/beds) to provide elder care services. To deregulate the eldercare market, the project required the government to relax restrictions and lower the market barriers in order to attract local investors to participate in the care industry. As the Executive Yuan organised inter-ministry discussions on modifications to the law, many social welfare groups and non-profit organisations who had been cooperating with local governments in providing long-term care services pressured the Ministry of the Interior to oppose the marketisation proposal (interview with NGO, December 2014). The CEPD also encountered difficulty in attracting local investors because of the uncertainty of the local long-term-care market. In the end, the marketisation proposal was halted, and the elder care service providers remained limited to non-profit organisations and small for-profit organisations.

While the Taiwanese government intended to push for marketisation and deregulation of the eldercare sector, the strong opposition from civil society actors forced the government to drop the policy proposal. Unlike the situation in Mainland China, where the government can push for top-down policy changes, democratic Taiwan showed a more pluralistic decision-making mechanism and needed to account for actors from various social groups (Chien, 2018).

Another example was when the KMT government pushed the Long-Term Care Insurance (LTCI) policy proposal after returning to office in 2008. During the presidential election campaign, in order to compete against the thenincumbent DPP government, KMT's presidential candidate, Ma Ying-Jeou, pro- 
posed a social insurance approach to implement the LTCI as an extension of the National Health Insurance, following the experiences of Japan where longterm care insurance was introduced in 2000 after the Golden Plan. After Ma was elected, his LTC I proposal faced strong opposition from civil society groups and the legislature. Specifically, the Federation for the Welfare of the Elderly and the League for Persons with Disabilities argued that with limited infrastructure for public care services, the LTCI would incentivise for-profit corporations to enter the care industry, leading to further marketisation of long-term care services. Feminist groups also criticised the government's LTCI draft for unfairly excluding families who hired migrant care workers. Finally, Taiwan's Industry and Commerce Association, representing the interests of Taiwanese business owners, rejected the government's LTCI proposal, as it required employers to contribute $60 \%$ of the premium for each employee (interview with NGO, December 2014). In the face of this strong opposition, the кмт government decided to postpone the LTCI proposal. Here again, the strong political alliances from the civil society influenced the policy debates and shaped the policy development of elder care in Taiwan. The KMT government was forced to move away from marketisation options and get more involved in providing elder care.

As society continues to demand for more services, the Taiwanese government responded by extending the eldercare provisions and increasing the fiscal budget for this sector. In April 2005, a minister without a portfolio, Fu Li-Yeh, initiated the Long-Term Care System Planning Small Group, the first interministry policy planning committee focusing on Taiwan's long-term eldercare, to push for further development of the elder care sector's infrastructure. After years of planning, the government introduced its Ten-Year Long-Term Care Plan in 2007, the first official plan for the national long-term care service system. The government planned to spend NT $\$ 81.7$ billion (CAD $\$ 3.5$ billion) over a ten-year period (2007-2016) to build the infrastructure for the long-term-care service system and made it the top policy priority on the political agenda (Lin, 2010). In 2015, the Legislative Yuan (congress) passed the Long-Term Care Service Act (LTCSA) to provide integrated and comprehensive regulations for long-term care institutions, including nursing homes, residential care centres, daycare centres, and care centres for persons with disabilities.

In December 2016, the Taiwanese government included community services and respite residential care for its elderly citizens and lowered the age limits and requirements for the care recipients. According to a government report in $2017,76.12 \%$ of the citizens agree that the government's eldercare services are helpful in providing necessary eldercare needs. Also, for people who have utilised the government's eldercare system in the past year, more than $97 \%$ 
expressed their satisfaction with the services (Taiwan's Ministry of Health and Welfare, 2017). ${ }^{14}$ Therefore, in the following years, the government continued to extend service coverage and provide professional training for social workers and government certified elder care workers.

Currently, the policy debates around eldercare services focus on possibility of adopting community care systems like those in the Nordic countries. The ruling DPP party intends to maintain the current tax-based system and continue to extend government services, instead of leaving the care responsibilities to the families. ${ }^{15}$ In other words, contrary to what the Confucianism welfare state literature would have predicted, the Taiwanese government has continued to extend elder care services and shift responsibilities from the family to the public sphere in response to the demands from social organisations and broader civil society actors.

\section{Discussion and Conclusion}

This paper focused on the policy legacies of eldercare development in China and Taiwan. It has demonstrated that, in the case of China, the re-familialisation of elder care is the byproduct of reform policies, "filial" legislation, as well as their respective unintended consequences on the pension and medical sectors; in the case of Taiwan, the progressive defamilialisation of eldercare is partly the product of its democratic process and the result of competing political interests.

In the early 1950s, the party-state started to enforce family-centred elder care rules, while at the same began providing extensive welfare through its commune and working-unit system. However, with the dismantling of the commune system and early economic reform policies that began in the late 197os,

142017 Seniors Survey, Ministry of Health and Welfare, Taiwan (R.O.C): https://dep.mohw.gov .tw/DOS/cp-1767-38429-113.html (access 2019 Dec 24).

15 Many Taiwanese families choose to recruit migrant care workers from Southeast Asian countries to provide eldercare at home. For many scholars, it may seem to be an equivalent to the traditional familial care model as the families can "outsource filial piety" to the migrant workers (Lan, 2006). While the labor shortage in the care market is a problem in the Taiwanese society, the Taiwanese government has been working to integrate the migrant workers into the eldercare system instead of leaving them in private households. For example, the government allows care institutions to hire migrant care workers to provide both institutional care and home visits services (so many families can jointly hire one migrant care worker). The government also recently allowed families who hire migrant care workers to use public respite service. 
as well as the implementation of a new series of laws and regulations (e.g., the household responsibility system), the Chinese state slowly retreated and displaced care responsibilities and its fiscal burden onto the family unit, thus, creating (inflating) the supply and demand for familial care at the expense of institutional care. Since the mid-2ooos and early 2010s, the Chinese party-state has been pushing towards new local and national initiatives and has been trying to expand the role of local communities in order to create a sort of social net that would help in easing the current elder care crisis.

That said, the Party keeps updating its "filial laws" and overtly talking about the importance of traditional filial culture, leaving elder care arrangements in a dire predicament. To this effect, especially when considering how "traditional culture" and "Confucianism" were treated under communist rule, we see it more fit to talk about "filiality" by design, rather than being an expression of actual filial culture. Furthermore, as attitudes towards "traditional care" change (and have been for a while now), some local structures have even taken upon themselves to police and publicly shame non-filial children (Connor, 2016), leaving us to wonder to what extent the cultural argument might still apply.

The case of Taiwan, the democratic transition has fundamentally changed the policy-making process of social welfare policies since the 1980s. Electoral competition has been a main driver of social policy reforms. The кмT conservative government launched welfare reforms -including universal healthcare insurance, a public pension scheme and extending social welfare provisionsimmediately after the democratic transition. This was due to the fact that they were compelled to be responsive to electoral demands to secure their electoral success and, at the same time, to reduce any lasting association with the previous authoritarian regimes. In the same vein, when the DPP (the main grassroots opposition party since the authoritarian period) was elected to office, they launched the Long-Term Care System Development Pilot Project in May 2000 and introduced its Ten-Year Long-Term Care Plan in 2007, which was the first official plan for the national long-term care service system. The reasons as to why DPP party emphasised social policy issues were not only due to their working-class constituency, but also because of the changing electoral demographics - for example, the increasing numbers of working women and young voters. All parties worked to secure votes, and more political actors influenced the social policy-making process. Through such social policy deepening, the Taiwanese government continues to socialise the burden of elder care away from the family to the public. Unlike what the literature on Confucian welfare state would predict, Taiwan (despite changes of government) has been actively shifting the care responsibilities from the family to the public and the state. 
In terms of developments in the overall eldercare arrangement, if we compare Mainland China and Taiwan, which some are labelling "Confucian welfare states," different regime types did indeed produce different outcomes. However, remnants of familialism are more likely attributable to policy legacies, rather than "Confucian culture," even if both sides of the strait engaged with traditional culture from a vastly different angle.

It is also important to note that China and Taiwan's elder care arrangements are constantly being negotiated between the state and civil society. In this regard, China's current trend of "defamilialisation" might resemble that of Taiwan, or even Singapore in the near future. In this respect, in contrast to Taiwan or even China, Singapore stands out as a more explicit case of government-led institutionalised Confucian values. The government has progressively implemented a series of measures to provide sanctions and incentives for citizens to make available eldercare services; a situation that is now not too dissimilar to what the party-state is trying to accomplish (minus the formalised incentives). In addition, government imposed filiality, which came after decades of disregard and substitution in China, has been implemented almost all at once, raising dramatic economic and social contradictions.

For Taiwan, and even to a certain extent Japan, the trend is not towards the institutionalisation of Confucian values, but rather a slow movement towards a more "Westernised" form of elder care socialisation. Not unlike Taiwan, the Japanese government progressively implemented policies aimed at extending support for both families and the elderly through social care provisions, resulting in a progressive defamilialisation of elder care. That said, there is more to learn from these culturally similar cases which would suggest that "traditional culture" might be less of a factor in the overall development of eldercare than what the proponents of the cultural variable would lead us to believe.

As previously mentioned, the article is limited in terms of scope and possible generalisations simply because several variables are not accounted for, nor controlled (population size, economic structure, etc.). That said, through the lenses of path dependency, we were able to highlight the importance of policies, instead of culture, on the current elder care arrangements. In this respect, we have tried to uncover the possible sources of the enduring "familial" elements in the eldercare structures of both China and Taiwan; some of the conclusions could be of interest for other cases like Japan and Singapore, cases that share a similar cultural background but also developed dramatically different elder care arrangements. In this regard, the article does make a strong case for more emphasise to be put on policy legacies in order to possibly understand other cases' care predicament. 


\section{References}

Abrahamson, Peter (2017) "East Asian Welfare regimes: Obsolete ideal-type or diversified reality?" Journal of Asian Public Policy 10(1): 90-103.

Alber, Jens and Guy Standing (2000) "Social Dumping, catch-up or convergence? Europe in a Comparative Global context." Journal of European Social Policy 10(2): 99119.

An, Yunfeng (2009) "Hongyang chuantong xiaodao wenhua, guanzhu nongcun yanglao wenti." (Carry forward the traditional filial culture, be warry of the rural pension issue.) Qilu Wenli 5: 73-78.

Baldock, John (1999) "Culture: The missing variable in Understanding Social Policy?" Social Policy and Administration 33(4): 458-473.

Barr, Michael D. (2002) Cultural Politics and Asian values: The tepid war. London: Routledge.

Bauer, Joanne R. and Daniel A. Bell (eds.) (1999) The East Asian Challenge for Human rights. Cambridge: Cambridge University Press.

Bell, Daniel. A. (2016) The China Model: Politicalmeritocracy and the limits of democracy. Princeton: Princeton University Press.

Bell, Daniel A. and Chenyang Li (eds.) (2013) The East Asian Challenge for Democracy. PoliticalMeritocracy in a Comparative perspective. Cambridge: Cambridge University Press.

Bode, Ingo (2007) The Culture of the Welfare Markets: The International Recasting of pension and Care systems. New York: Routledge.

Cai, Fang, John Giles and Xin Meng (2006) "How well do children insure parents against low retirement income? An analysis using survey data from urban China." Journal of Public Economics 9o(12): 2229-2255.

Cheung, Chau-Kiu and Yui-Huen Kwan (2009) "The erosion of filial piety by modernisation in Chinese cities." Ageing and Society 29(2): 179-198.

Chien, Yi-Chun (2018) "The Struggle for Recognition: The Politics of Migrant Care Worker Policies in Taiwan." Critical Sociology 44(7-8): 1147-1161.

Chou, Jing-Ann (2011) "Filial Piety by contract? The emergence, implementation and implications of the 'family support agreement' in China." Gerontologist 51(1): $3^{-16}$.

Connor, Neil (2016) "China village names and shame people who neglect their parents." The Telegraph, July 31st 2016. Available at: https://www.telegraph.co.uk/news/2016/ o7/31/china-village-names-and-shames-people-who-do-not-take-proper-car/?fbcli d=IwARoN74otrMaOz7-xlWVcZlIIvaVulPkCqfU5YJ25lM5TUTGHeyVBi67yhNI.

De Bary, Wiliam Theodore (1998) Asian values and human rights. A Confucian communitarian perspective. Cambridge: Harvard University Press.

Du, Qihong and Qing Liu (2014) “4-2-1 jiating yanglao da kaoyan.” (421 family pension's major challenge.) Zouxiang shijie 41: 24-26. 
Fan, Ruiping (2010) Reconstructionist Confucianism: Rethinking Morality after the West. New York: Springer.

Feng, Zhanliang and Elena Glinskaya (2018) Options for Aged Care in China: Building an efficient and sustainable aged care system. Washington, D.C.: World Bank Group.

Feng Zhanlian, H.J. Zhan, X.T. Feng, C. Liu, M.Y. Sun and Vincent Mor (2011) "An Industry in the making: The emergence of institutional elder Care in Urban China." Journal of the American Geriatrics Society 59(4): 738-744.

Fung, Ho-Lup (2001) “The Making and Melting of the 'Iron Rice Bowl' in China 1949 to 1995." Social Policy and Administration 35(3): 258-273.

Goodman, Roger, Gordon White and Huck-Ju Kwon (eds.) (2006) The East Asian Welfare Model. Welfare Orientalism and the State. New York: Routledge.

Hao, Yan (1997) "Old-age support and care in China in the 199os." Asia Pacific Viewpoint 38: 201-217.

Jones, Catherine F (1993) “The Pacific Challenge: Confucian Welfare State," in Catherine Jones (ed.) New Perspectives on the Welfare State. London: Routledge, Pp. 199-217.

Kim, So Young (2010) "Do Asian Values Exist? Empirical Tests of the Four Dimensions of Asian Values." Journal of Asian Studies 10(2): 315-344.

Lee, Ilhak (2015) "Filial Duty as the Moral Foundation of Care for the elderly: Its Possibility and Limitations," in Ruiping Fan (ed.) Family-Oriented Informed Consent. East Asian and American Perspectives. New York: Springer, Pp. 137-147.

Lee, James and Kam-Wah Chan (eds.) (2007) The Crisis of Welfare in East Asia. Lanham: Rowman \& Littlefield Publishers.

Leung, Lai Ching (2014) "Gender Mainstreaming Childcare Policy: Barriers in a Confucian Welfare Society." Journal of International and Comparative Social Policy 30(1): 41-52.

Li, Chenyang (2010) "The Confucian concept of Ren and the Feminist ethics of Care: A comparative study," in Daniel A. Bell (ed.) Confucian Political Ethics. Princeton: Princeton University Press, Pp. 175-199.

Lichbach, Mark Irving and Alan S. Zuckerman (eds.) (20o9) Comparative Politics. Rationality, Culture and Structure. Cambridge: Cambridge University Press.

Lin, Chin-Ju (200o) "The State Policy that Divides Women: Rethinking Feminist Critiques to 'the Foreign Maid Policy in Taiwan.” Taiwan: A Radical Quarterly in Social Studies 39: 93-151.

Lin, Ka (1999) Confucian Welfare Cluster: A cultural Interpretation of Social Welfare. Tampere: Tampere University Press.

Lin, Wenyi (2014) "Challenges of Long-term Care provisions for the elderly in Urban China." China: An International Journal 12(2): 144-16o.

Liu Suqun (2009) "Linzhong guanhuai zaiwoguo de Shijian yingyong ji fazhan duice yanjiu." (Research on the application and development of hospice care in China.) M.A dissertation, Shandong University. 
Ma Hong (1992) Zhongguo gaige quanshu: Laodong gongzi tizhi gaige juan, jiage tizhi gaige juan, touzi tizhi gaige juan 1978-1991. (Comprehensive book on Chinese reforms: labor wage system reform dossier, price system reform dossier, investment system reform dossier.) Dalian: Dalian Publishing House.

Mok, Ka Ho, Stefan Kuhner and Genghua Huang (2017) "The Productivist Construction of selective welfare pragmatism in China." Social Policy and Administration 51(6): $876-897$.

Nie, Jingbao (2015) “The Benevolent Polity: A Confucian Socio-Ethical Vision of Eldercare." Asian Bioethics Review 7(3): 26o-276.

Oorschot, Wim van, Michael Opielka and Birgit Pfau-Effinger (eds.) (2008) Culture and the Welfare State: Values and Social Policy in Comparative Perspective. Cheltenham: Edward Elgar Publishing.

Peng, Ito (2017) "Explaining Exceptionality: Care and Migration Policies in Japan and South Korea," in Sonya Michel and Ito Peng (eds.) Gender, Migration, and the Work of Care: A Multi-Scalar Approach to the Pacific Rim. Cham: Springer International Publishing, Pp. 191-214.

Peng, Ito and Yi-Chun Chien (2018) "Family policy models: East Asian Cases," in Guðný Björk Eydal and Tine Rostgaard (eds.) Handbook of Child and Family Policy. Cheltenham: Edward Elgar Publishing.

Peng, Ito and Joseph Wong (2008) "Institutions and institutional purpose: Continuity and change in East Asian social policy." Politics and Society 36(1): 61-88.

Peng, Ito and Joseph Wong (2010) "East Asia," in Stephan Leibfried, Francis G. Castles, Jane Lewis, Herbert Obinger and Christopher Pierson (eds.) The Oxford Handbook of the Welfare State. Oxford/New York: Oxford University Press, Pp. 656-67o.

Ren, Yiyang (2013) “Duoyuanhua shequ yanglao fuwu yanhjiu." (Research on the Diversity of Community Endowment Service.). M.A. dissertation, Northwest Normal University (Gansu).

Sciubba, Jennifer Dabbs, and Chien-Kai Chen (2017) "The Politics of Population Aging in Singapore and Taiwan. A Comparison." Asian Survey 57(4): 641-664.

Sen, Panama (2014) "Do Asian Values still Exist? Revisiting the Roots in Search of a Plausible Future." South Asian Survey 21(1-2): 51-63.

Stockman, Norman, Norman Bonney and Xuewen Sheng (2016) Women's work in East and West: The Dual burden of Employment and family life. New York: Routledge.

Sung, Sirin and Gillian Pascall (eds.) (2014) Gender and Welfare States in East Asia: Confucianism or Gender equality? New York: Springer.

Tang, Kwong-Leung (2000) Social Welfare Development in East Asia. New York: Palgrave Macmillan.

Tremblay, Diane-Gabrielle and Elisabeth Pernigotti (2014) "Between Continuity and Change: Economy of Policy of Care and Domestic Work. Introduction." Papers in Political Economy 51: 1-7. 
Walker, Alan and Chack-kie Wong (eds.) (2005). East Asian Welfare Regimes in Transition: From Confucianism to Globalization. Bristol: The Policy Press.

Wang, Yanzhong and Dasheng Shan (2015) "Improving the Social Security system," in Luolin Wang (ed.) China's WTo Accession Reassessed. New York: Routledge, Pp. 119140.

Welzel, Christian (2011) "The Asian Values Thesis Revisited: Evidence from the World Values Surveys." Japanese Journal of Political Science 12(1): 1-31.

Wong, Joseph (2004) Healthy democracies: Welfare politics in Taiwan and South Korea. Ithaca: Cornell University Press.

Wu, Yushao and Ping Guo (eds.) (2014) 2010 nian zhongguo chengxiang laonian renkou zhuangkuang zhuizong tiaocha shujifenxi. (Data Analysis of the Sampling Survey of the Aged Population in Urban Rural China 2010.) Beijing: Beijing Social Press.

Yang, Nan (2017) "East Asia in transition: Re-examining the East-Asian welfare model using fuzzy sets." Journal of Asian Public Policy 10(1): 104-120.

Yeh, Kuang-hui, Chin-Chun Yi, Wei-Chun Tsao and Wan Po-San (2013) "Filial piety in contemporary Chinese societies: A comparative study of Taiwan, Hong Kong, and China." International Sociology 28(3): 277-296.

Zhang, Qian (2012) "Nongcun jiating jiegou bianqian yu jiating yanglao baozang de zai dingwei." (Rural Families Structural Changes and Re-positioning of the Family Oldage Security.) Ha'erbin shangye daxue xuebao 6: 112-117.

Zhang, Shang (1983) Zhonghua renmin gongheguo xingfa gai lun: zongzibufen. (Paradox of the People's Republic of China's criminal law: General provisions.) Beijing: Law Press.

Zhang, Yinghua and Jiang Yan (2015) "Zhongguo yanglao fuwu xianzhuang, wenti yu gonggong zhengce xuanze." (The Status, Problems and Public Policy Selection of Elderly Care Service System in China.) Dangdai Jingji Guanli 37(1): 51-56.

Zhao, Zhongwei, Hongbo Jia and Jiaying Zhao (2017) "Health inequalities, medical insurance and medical financial assistance," in Beatriz Carrillo, Johanna Hood and Paul Kadetz (eds.) Handbook of Welfare in China. Cheltenham: Edward Elgar Publishing, Pp. 98-122.

Zheng, Yongnian (2007) De Facto Federalism in China. Reforms and Dynamics of CentralLocal Relations. Singapore: World Scientific Publishing.

Zhu, Kezhen and Jun Chen (2013) “Linzhong guanhua de zhexue yu zongjiao shentou." (The infiltration in hospice care of philosophy and religion.) Yixue Lilun 4(6): 19-22. 